\title{
Large-scale variation in seasonal swimming patterns of plaice in the North Sea
}

\author{
E. Hunter ${ }^{1, *}$, R. J. Cotton ${ }^{2}$, J. D. Metcalfe ${ }^{1}$, J. D. Reynolds ${ }^{3}$ \\ ${ }^{1}$ Centre for Environment, Fisheries and Aquaculture Science, Lowestoft Laboratory, Pakefield Road, Lowestoft, \\ Suffolk NR33 0HT, UK \\ ${ }^{2}$ Mathematical Sciences Unit, Health \& Safety Laboratory, Harpur Hill, Buxton, Derbyshire SK17 9JN, UK \\ ${ }^{3}$ Department of Biological Sciences, Simon Fraser University, Burnaby, British Columbia V5A 1S6, Canada
}

\begin{abstract}
We examined the mid-water swimming activity of 139 mature female plaice Pleuronectes platessa L. These were tagged with electronic data storage tags (DST1s and DST3s) to test whether swimming at different times of the year differed among areas of the North Sea with average tidal current velocities ranging from fast (West), to intermediate (East), to slow (North). Longer swimming duration and more tidal activity were predicted for the western group, where fast-flowing tidal currents allow efficient selective tidal stream transport. Individual depth data were converted into binary records representing either swimming or resting; repeated patterns of swimming were analysed according to cycle-length frequencies. Most swimming occurred during expected times of migration and spawning (October to March). Plaice infrequently spent $>5 \mathrm{~h}$ in mid-water, and rarely left the sea-bed during summer. DST1 tagged plaice (West only) spent the longest times swimming ( $p>0.001$ ), but there was no significant effect of Area for DST3s (all areas), suggesting that swimming plays an important behavioural role in migration in addition to transport between feeding and spawning areas. Tidal patterns of activity occurred in all 3 sub-stocks, predominantly during the migratory period (albeit at a significantly lower frequency in the North). These data provide one of few examples where the annual behaviour patterns of a fish stock have been recorded across a large part of its geographical range. The results have important implications for understanding the energetics of fish migration and the availability of demersal stocks to capture by commercial and survey vessels.
\end{abstract}

KEY WORDS: Plaice $\cdot$ Migration $\cdot$ Data storage tags $\cdot$ Swimming $\cdot$ Behaviour $\cdot$ Fisheries

\section{INTRODUCTION}

Despite recent technological advances in the methods available to biologists to measure the behaviour of marine fish in their natural environment (e.g. Pittman \& McAlpine 2003, Metcalfe et al. 2008b), the varying seasonal behaviour patterns of individual species across their distribution ranges remain enigmatic. Many commercially exploited fish species follow extensive annual migration circuits which are often contained within oceanic circulation systems (Metcalfe et al. 2002). Such migrations can occur either at the oceanic level using ocean currents (e.g. Block et al. 2005), or more locally on the continental shelves using the tides (e.g. Metcalfe et al. 2006); this allows fish to minimise the energetic costs associated with largescale migration through the use of environmental transport systems, a technique also employed by taxa as diverse as insects (e.g. Brower 1995) and birds (e.g. Alerstam 2006).

On the European continental shelf, where tidal currents dominate, the use of environmental transport by plaice Pleuronectes platessa throughout their life histories has long been recognised (Metcalfe et al. 2006). Like many other bottom-dwelling fish, spawning by plaice occurs in well-defined spawning areas located upstream of the nursery grounds used by juvenile fish; residual currents are responsible for passively trans- 
porting eggs and larval plaice onto the coastal nursery grounds. The developing juvenile fish then maintain their position in the inter-tidal zone by adopting a system of tidal transport, allowing the fish to make feeding excursions onto the mud flats during times of high water (Kuipers 1973), then retreating below the lowwater mark before the expected time of low tide.

In areas of fast-flowing tidal currents, adult plaice are known to adopt activity patterns in phase with the tidal currents (Hunter et al. 2004c). During autumn and winter for example, southward-migrating plaice in the southern North Sea leave the seabed during southflowing tides; they then swim directly down-tide until the time of slack water (Buckley \& Arnold 2001), at which time they return to the seabed where they remain for the duration of the north-flowing tide. This behaviour is then repeated; a pattern of activity termed selective tidal stream transport (STST: Weihs 1978), which allows rapid and efficient movement between geographically distant feeding and spawning areas (Metcalfe et al. 1990). Conversely, on the feeding and spawning grounds, plaice often swim only at night (Hunter et al. 2004c); as the day-night cycle is out of phase with the tidal cycle, it has been proposed that this activity pattern leads to a random distribution of the fish around the spawning and feeding areas (Harden Jones et al. 1979, Arnold 1981).

Although continuous electronic data storage tag (DST) behaviour records of migrating adult females have clearly linked STST to the pre-spawning and post-spawning migrations of plaice in areas of fastflowing tidal currents (Hunter et al. 2004c), plaice form at least 3 major feeding aggregations throughout the North Sea during the summer (Hunter et al. 2004b): these are located in the western, eastern, and central northern North Sea. While the eastern aggregation is also located near a fast-flowing tidal stream, the northern aggregation is located in an area of slow-flowing tidal currents where it is predicted that most plaice would be unable to gain any energetic advantage by using the tidal streams to migrate (Metcalfe et al. 1990). The behaviour of plaice in both of these areas has received much less attention, and previous studies have assumed that migration in the central northern North Sea has been achieved by directed swimming across the sea bed, as opposed to swimming in midwater (Hunter et al. 2003).

These behaviours have important implications for the assessment of marine fish stocks, particularly for seabed dwelling species such as plaice (e.g. Casey \& Myers 1998, Benoit \& Swain 2003). The application of technical conservation measures (designed to protect against over-exploitation) frequently make assumptions concerning availability and catchability which cannot be validated (Kell \& Fromentin 2007); addition- ally, assumptions about the rates, scales and timing of horizontal and vertical movements are largely untested (Bjørndal et al. 2004). Variation in any of these factors can significantly affect abundance estimates derived from trawl-based and sonar-based surveys (Aglen et al. 1999). For example, not only is movement of fish between stock management areas considered to be negligible (Kell et al. 2004), but the availability of fish to capture by fishing vessels is also generally assumed to be constant throughout the year. For many species this assumption is unlikely to be true (e.g. Poos \& Rijnsdorp 2007) since many studies have shown the activity levels of individual fish to be linked to the annual reproductive cycle (e.g. Michalsen et al. 1996, Nichol \& Somerton 2002, Hobson et al. 2007).

In this study we used data from free-swimming mature female plaice; tagged with DSTs and released at a variety of sites with contrasting tidal properties across the North Sea to quantify (1) the total amount of time spent swimming in mid-water, and (2) spatial and temporal variation in patterns of mid-water swimming. The study was designed to determine whether plaice from areas with differing tidal characteristics varied the amount of time spent swimming in mid-water at different times of year, and whether differences in the timing of the swimming episodes could be detected.

It was predicted that fish in the western North Sea (where tidal currents are fast and have predominantly bidirectional tidal flow patterns) would exhibit more time swimming in mid-water during periods of migration than plaice in the northern North Sea (where tidal currents are slower, and therefore provide less energetic advantage to the fish). Furthermore, it was predicted that behaviour patterns consistent with STST behaviour would not be observed in migrating northern plaice. The results of this study have important implications for the overall understanding of the energetics of migration, and for predicting the availability of fish for capture by commercial and survey vessels.

\section{MATERIALS AND METHODS}

Release of plaice tagged with electronic data storage tags. The analyses draw on data from 2 major field programmes targeting mature female plaice in the North Sea; the first of these programmes released 302 fish tagged with DST1s (Cefas Mk-1 DSTs) between 1993 and 1997 (Hunter et al. 2004a), while the second programme released 452 plaice tagged with DST3s (Lotek-1200 DSTs, Lotek) between 1997 and 2000 (Hunter et al. 2004b).

The DST1 was the first mass-produced DST (Metcalfe \& Arnold 1997) and was designed specifically for use with flatfish, with a smooth hemispherical profile 


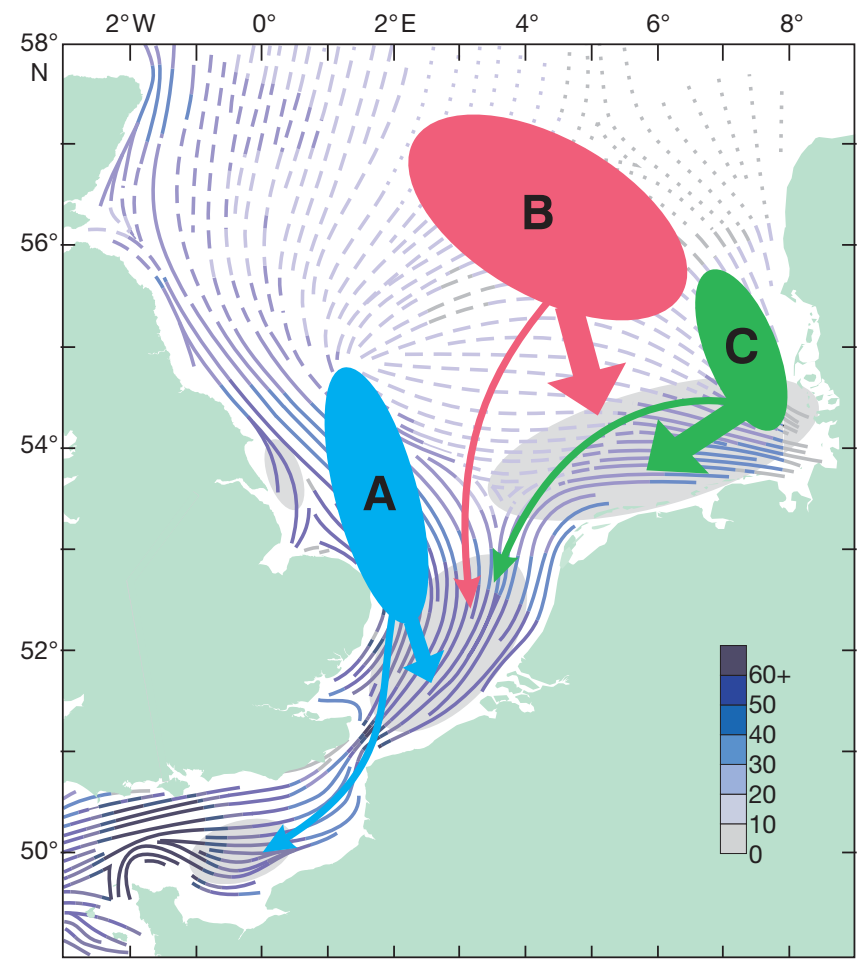

Fig. 1. Pleuronectes platessa. Summer location of plaice population sub-units; (A) western, (B) northern, and (C) eastern feeding aggregations, identified by Hunter et al. (2004b), with arrows indicating direction of spawning migrations. Location of spawning areas (grey shading) is shown in relation to tidal currents. Lines: direction of tidal flow (broken lines = weaker tidal currents). Line colours: average tidal current velocities across the study area (scale units $=\mathrm{cm} \mathrm{s}^{-1}$ )

and a flat base to sit flush on the flank of the fish (Metcalfe \& Arnold 1998). The DST1s were larger and heavier (23 $\mathrm{g}$ in seawater, $55 \mathrm{~g}$ in air) than the DST3s ( $2 \mathrm{~g}$ in water, $16 \mathrm{~g}$ in air), and hence were attached to larger fish (minimum size $=40 \mathrm{~cm}$ TL [total length], compared with $35 \mathrm{~cm}$ TL). Using Bannister's (1978) length/weight relationship for North Sea plaice [weight $(\mathrm{g})=0.00892$ length $\left(\mathrm{cm}^{3}\right)$ ], the DST1 in air represents at most $9.6 \%$ of the total mass of a $40 \mathrm{~cm} \mathrm{TL}$ plaice (compared with $0.04 \%$ for a $35 \mathrm{~cm}$ TL plaice tagged with a DST3).

The DST1s also had a shorter recording lifetime than the DST3s (maximum of $222 \mathrm{~d}$ compared with 18 mo). All tags were programmed to record depth (pressure) at $10 \mathrm{~min}$ intervals, and were returned through the commercial fishery.

The only other difference in methodology between the 2 release programmes was that fish in the DST1 programme were returned to the laboratory aquarium in Lowestoft (UK) following initial capture; they remained in the laboratory for $43 \pm 20 \mathrm{~d}$ before tagging and release at sea to allow recovery from any effects of capture. By contrast, all DST3-tagged plaice were tagged and released at sea, usually within 30 min of initial capture.

The 2 DSTs represent part of an evolving programme of research that was undertaken over a full decade; hence the DST1 was both larger and heavier than would be desirable by current technological standards, and significantly heavier than the '2\% tag/ bodymass rule of thumb' cited by Winter (1996). Consequently it has not been possible to standardise the physical and methodological differences between the 2 programmes. However Jepsen et al. (2005) note that recommendations on maximum ratios are often experimentally unfounded statements; in a brief review they cite several studies (e.g. Brown et al. 1999, Perry et al. 2001 ) in which fish with tags, representing up to $12 \%$ of body mass, appeared to be unaffected by the tags, at least in terms of the variable being measured. For the purposes of the current work, tag and tagging effects cannot be discounted when evaluating the results of the analyses described; however both DST1 and DST3 tagged plaice recorded full migrations, often over hundreds of kilometers.

Tagged plaice were released in areas of average tidal current velocities ranging from slow to fast (Fig. 1). However, for the purposes of the current study individual fish were grouped according to membership of the 3 population sub-units identified by Hunter et al. (2004b): western, northern and eastern feeding aggregations (Fig. 1).

Data download and processing. Raw data were converted into depth $(\mathrm{m})$ and temperature $\left({ }^{\circ} \mathrm{C}\right)$. From each activity record, the first 2 days of data were removed as a precaution to eliminate behavioural alteration caused by tagging; incomplete days at the end of tag records were additionally removed. In order to avoid the rise and fall of the tide being falsely interpreted as depth transitions, changes of $\geq 3 \mathrm{~m}$ between successive 10 min measurements were assumed to indicate transition from on-bottom to mid-water swimming (Hunter et al. 2004c); this approach was further complemented by the swimming behaviour of plaice, which tend to swim up into mid-water for protracted bursts of activity (Greer-Walker et al. 1978) using 'burst and glide' locomotion (Priede \& Holliday 1980). This gauge was used to convert the depth record into a binary file of activity, or 'swimming' (= 1) versus inactivity (resting on seabed, $=0$ ). The total daily time spent swimming was then calculated for each fish as a percentage.

Analysis of swimming times. For each tagged fish, the mean daily time in mid-water was calculated by location in the sea and by month. It was assumed that the monthly swimming patterns were consistent across years, therefore annual means were not calculated separately. Initial exploration of the right-skewed data indicated a requirement for data normalization, there- 
fore a 4 th root transformation of mean daily swimming time was applied based on the method of Box \& Cox (1964, as described in Venables \& Ripley 2002), to satisfy the criteria for ANOVA. The 4th root transformation reduces the effect of large observations and focuses the analysis on the smaller values that made up the majority of the dataset. An analysis of variance was then performed with the factors Month, Area (=Subunit) and Tag-type.

Both the DST1 and DST3 experiments were conducted with a series of batch releases, and it was therefore possible to apply ANOVA to further test for differences between batches, areas and tag-types.

Analysis of swimming patterns. A cycle-length frequency analysis was used in order to look at patterns of swimming activity. Cycle-length was determined using only data records of $\geq 1$ mo duration to avoid bias towards short cycle lengths. Because most fish were released in the winter months, fewer data were available during the summer.

Very short periods of swimming activity (defined as isolated $0 \mathrm{~s}$ and $1 \mathrm{~s}$ in the 10-min-interval time series) were considered to be noise in the data, and their state was therefore changed (e.g. 101 became 111 and 010 became 000). Periods, defined as the length of time each individual remained in a particular state (i.e. persisted in swimming or resting), were determined for each record by counting the number of consecutive values before a state change. A cycle was then defined as one rest period followed by one swimming period.

The frequencies of all cycles summed over all records were calculated, and a smoothed curve was drawn through the data points. This curve was created using a weighted central moving average filter, weighted 1/9,2/9, 3/9, 2/9, 1/9; that is: each data point was replaced by the sum of $1 / 9$ th of the data point 2 steps to the left $+2 / 9$ th of the data point one step to the left $+3 / 9$ of itself $+2 / 9$ th of the data point one step to the right $+1 / 9$ th of the data point 2 steps to the right. Analyses were carried out using unsmoothed data. At longer time scales, cycle lengths were grouped into intervals created by rounding the logarithm of the cycle length to the nearest 0.05 so that longer cycles appeared in wider intervals.

To quantify seasonal variation, the data were divided into monthly groups. A quantitative analysis of the change in cycle length was computed by pair-wise Wilcoxon tests using the method of correction of Benjamini \& Yekutieli (2001).

To compare variation in the level of tidal behaviour, the number of cycles over the months October-March inclusive was counted for each record, and the fraction of cycles that were tidal (defined in this instance to be cycles of length 7.5 to $17.5 \mathrm{~h}$ ) was determined. Oneway ANOVA was used to detect significant differences in tidal activity between subunits; pair-wise Wilcoxon tests (using Benjamini-Yekutieli adjustment) were used to determine which feeding groups the differences lay between.

\section{RESULTS}

\section{Return of tagged plaice}

Data were available from 139 returned tags (34 DST1s, 105 DST3s). From an estimated total of 27140 days at liberty, the returned DSTs recorded $19182 \mathrm{~d}$ of fish behaviour data $(71 \%)$, with individual data records ranging from 2 to $511 \mathrm{~d}$. The total number of days of data by tag type, subunit and month are presented in Table 1.

\section{Analysis of swimming times}

The box-plots in Fig. 2 illustrate mean daily swimming time by month. The fish spent most time in midwater during the time of expected migration and spawning (October to March) irrespective of the release location. On average the fish rarely spent $>5 \mathrm{~h}$

Table 1. Pleuronectes platessa. Number of days of plaice activity data by tag-type (DST1, DST3), area and month

\begin{tabular}{|c|c|c|c|}
\hline \multirow{2}{*}{ Month } & \multirow{2}{*}{$\overline{\text { East }}$} & \multirow{2}{*}{$\begin{array}{l}\text {-Area } \\
\text { North }\end{array}$} & \multirow[b]{2}{*}{ West } \\
\hline & & & \\
\hline \multicolumn{4}{|c|}{ Tag-type = DST1 } \\
\hline 1 & 0 & 0 & 516 \\
\hline 2 & 25 & 0 & 404 \\
\hline 3 & 31 & 0 & 408 \\
\hline 4 & 30 & 0 & 292 \\
\hline 5 & 31 & 0 & 226 \\
\hline 6 & 24 & 0 & 160 \\
\hline 7 & 0 & 0 & 104 \\
\hline 8 & 0 & 0 & 31 \\
\hline 9 & 0 & 0 & 30 \\
\hline 10 & 0 & 0 & 23 \\
\hline 11 & 0 & 0 & 0 \\
\hline 12 & 0 & 0 & 367 \\
\hline \multicolumn{4}{|c|}{ Tag-type $=$ DST3 } \\
\hline 1 & 438 & 1673 & 284 \\
\hline 2 & 306 & 1108 & 287 \\
\hline 3 & 310 & 1022 & 438 \\
\hline 4 & 284 & 741 & 324 \\
\hline 5 & 222 & 599 & 287 \\
\hline 6 & 182 & 474 & 194 \\
\hline 7 & 154 & 385 & 186 \\
\hline 8 & 93 & 372 & 174 \\
\hline 9 & 70 & 302 & 164 \\
\hline 10 & 81 & 458 & 357 \\
\hline 11 & 495 & 933 & 362 \\
\hline 12 & 554 & 1812 & 355 \\
\hline
\end{tabular}


swimming per day. Average swimming times in excess of $5 \mathrm{~h}$ per day were observed only for DST1 West fish during the months of December and January. Very little time was spent swimming in mid-water during the summer months, when few fish left the sea-bed at all.

Both the plot (Fig. 2) and the ANOVA of 4th root mean daily swimming times (with non-significant interactions removed) show differences between the DST1 (West area only) and the DST3 (all areas) mean swimming times (Tag-type, $\mathrm{p}=1.965 \mathrm{e}-12$ ), with higher swimming times for DST1 tagged fish (West only); this was most pronounced in December and January (Month, $\mathrm{p}<2.2 \mathrm{e}-16)$. The Area effect was not statistically significant $(\mathrm{p}=0.067)$. A further analysis using only the DST3 data also found no significant difference between areas ( $p=0.075)$, with the means of the transformed swimming times slightly higher in the East area, followed by West then North.

The individual release batches and number of tags returned with data in each batch are shown in Table 2. It was possible to compare the DST1 West batches, the DST3 North batches and the DST3 West batches. ANOVA indicated differences among DST3 North batches ( $p>0.001)$ and among DST3 West batches ( $p>$
Table 2. Pleuronectes platessa. Release batches of plaice tagged with electronic data storage tags (DST1, DST3), and the number of tags returned with data for each

\begin{tabular}{|lcr|}
\hline Area & Release batch & No. of tags \\
\hline West & 1.1 & 11 \\
West & 1.2 & 4 \\
West & 1.4 & 11 \\
West & 1.5 & 6 \\
East & 1.6 & 1 \\
North & 3.1 & 16 \\
North & 3.3 & 41 \\
North & 3.6 & 7 \\
North & 3.7 & 2 \\
East & 3.2 & 21 \\
West & 3.4 & 9 \\
West & 3.5 & 9 \\
West & 3.8 & 1 \\
\hline
\end{tabular}

0.001), but not among the DST1 West batches ( $\mathrm{p}=$ 0.175). For DST3 North, batch 3.1 had lower mean swim times than the other batches. For DST3 West, batch 3.5 had slightly lower swim times than batch 3.4 , and the tag in batch 3.8 had a higher swim time than the other batches.

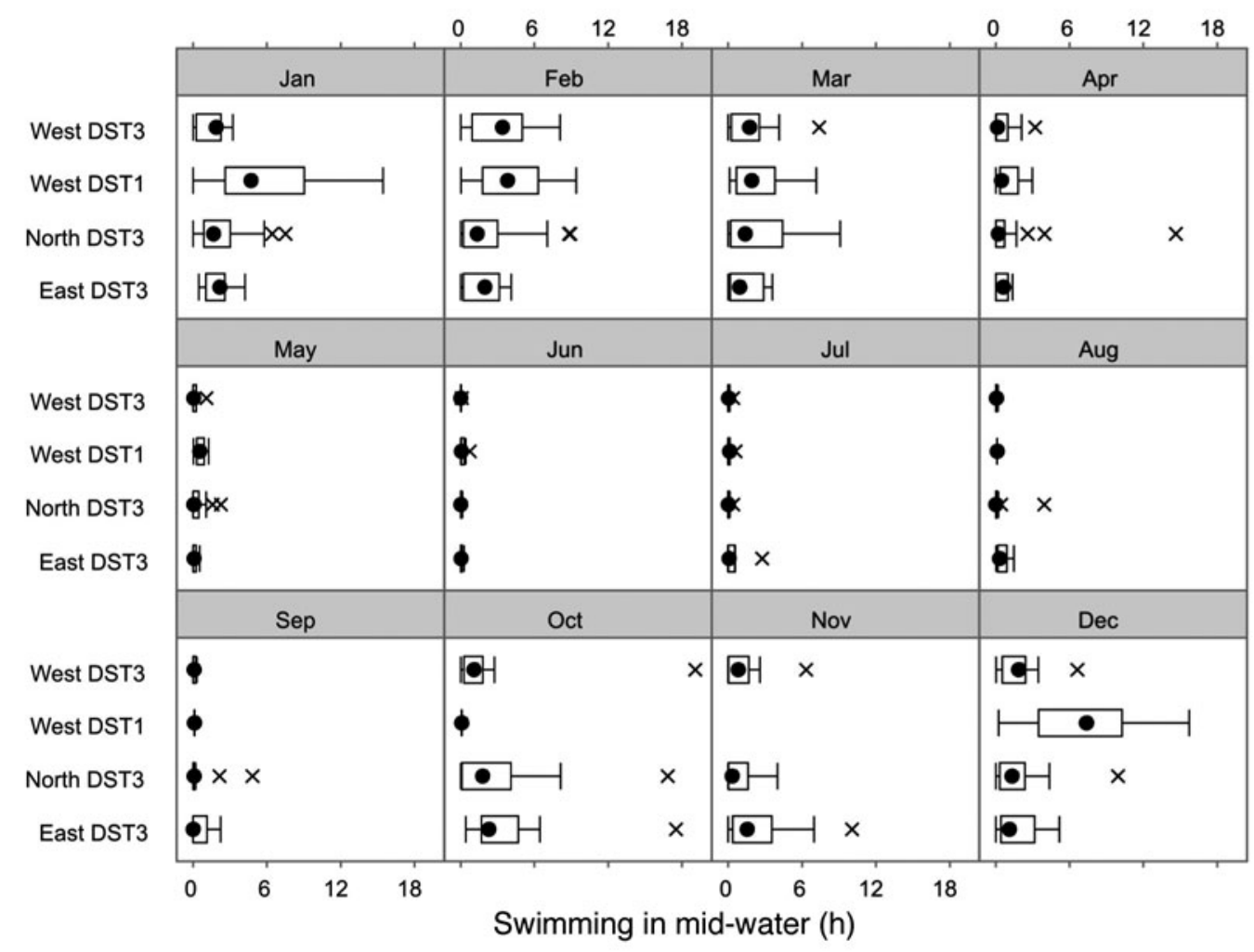

Fig. 2. Pleuronectes platessa. Mean daily time (h) spent swimming in mid-water by plaice tagged with electronic data storage tags (DST1 and DST3) and released in the North Sea, calculated by area (West, North, East) and month. Solid black dot: median; box: central $50 \%$ of the data (inter-quartile range, IQR); 'whiskers': furthest data points that are $<1.5 \times \mathrm{IQR}_{\text {; }}$ crosses: outliers 


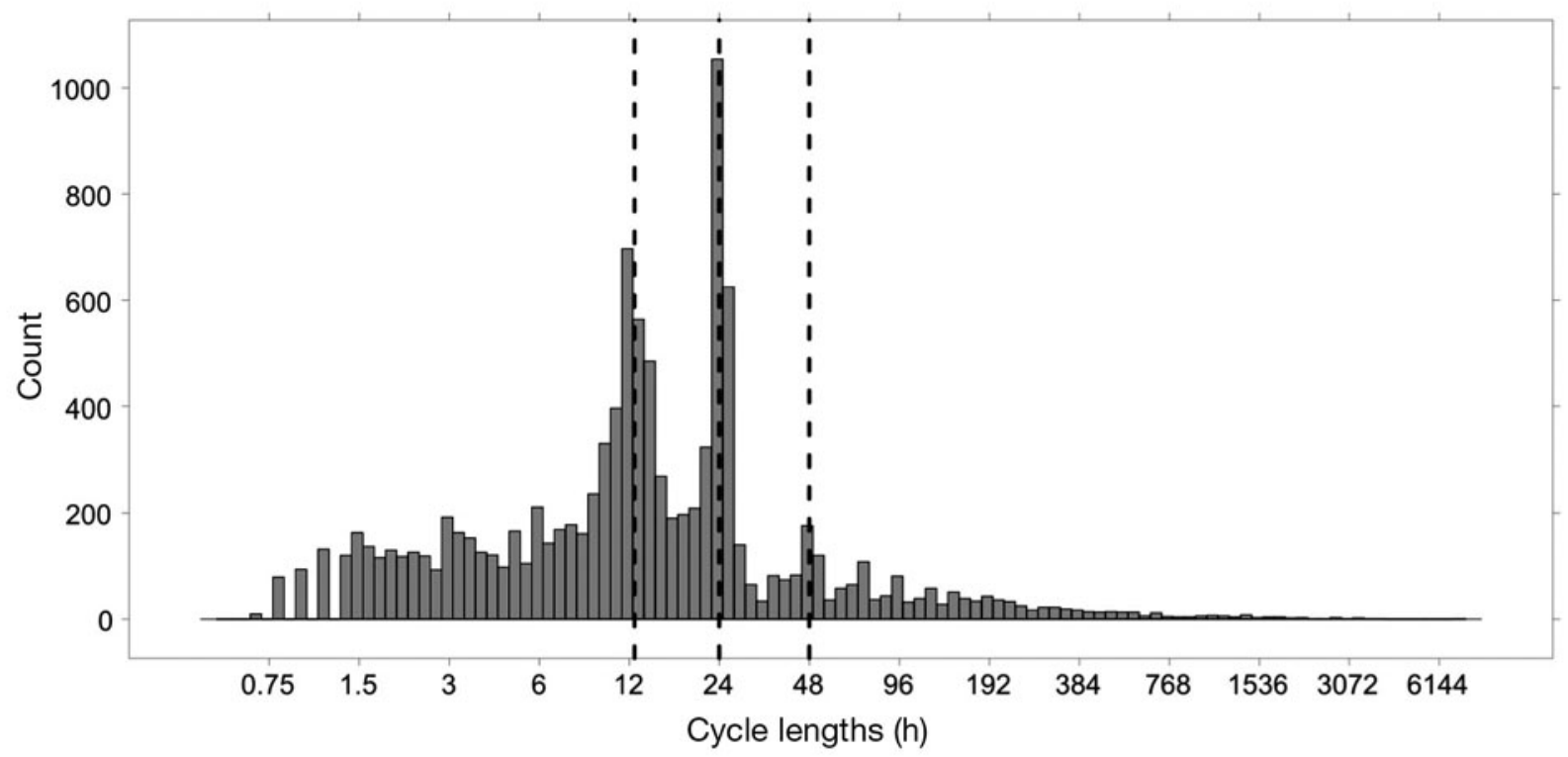

Fig. 3. Pleuronectes platessa. Frequency of occurrence of cycle lengths of swimming activity of North Sea plaice, using logarithmic binning. Vertical dashed lines: frequency peaks; representative of tidal, diel and multi-diel cycles

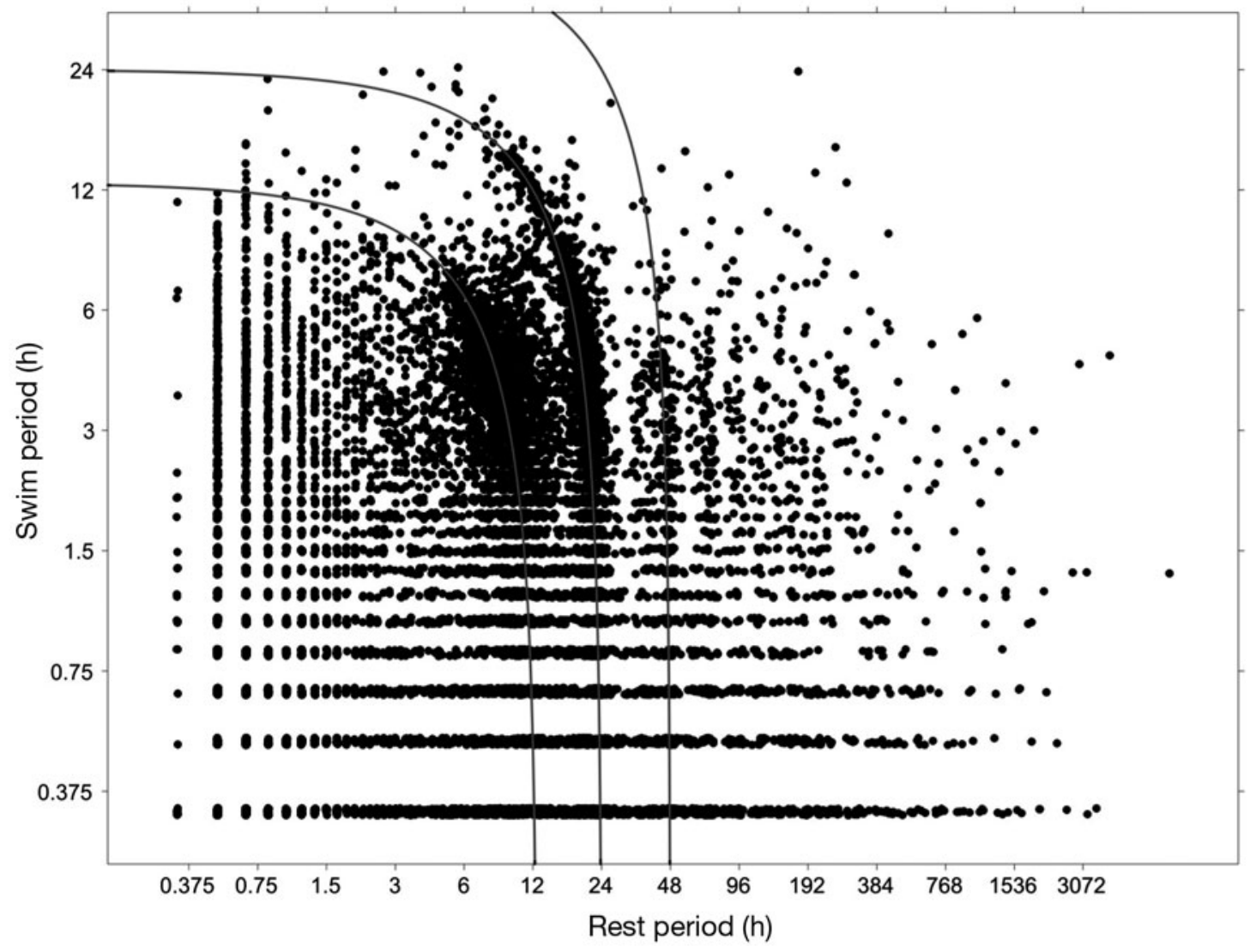

Fig. 4. Pleuronectes platessa. Relationship between swimming periods and rest periods in North Sea plaice. (Grey lines) cycles of 12.5, 24 and $48 \mathrm{~h}$. Short swim periods occurred for all cycle lengths, however longer swim periods occurred mainly in association with tidal or diel cycles 


\section{Analysis of swimming patterns}

Monthly sample sizes ranged from $\mathrm{n}=73$ fish in February to $n=19$ fish in September. The frequencies of cycle lengths detected within the sampled population are shown in Fig. 3. The peak at $12.5 \mathrm{~h}$ denotes tidal periodicity, while peaks at $24 \mathrm{~h}$ and $48 \mathrm{~h}$ denote diel and bi-diel activity respectively. Note that bi-diel activity is swimming for part of one day, then resting for the remainder of that day and all the following day, before swimming again, and is not, therefore, a harmonic repeat of diel behaviour. There also appears to be an excess of cycles close to 72 and $96 \mathrm{~h}$, indicating swimming every third or 4th day, however there was insufficient data at higher cycles to discriminate from background noise in the data.

The relationship between swim period and rest period for all records is shown in Fig. 4. The almost unbroken horizontal lines near the bottom of Fig. 4 show that short swim periods (up to $3 \mathrm{~h}$ ) occurred paired with rest periods of all lengths. By contrast, longer swim periods occurred more as part of tidal, diel (and to a lesser extent multi-diel) cycles.

Treating the population as a whole, the significance of differences between cycle lengths by month is shown in Fig. 5. Consecutive months with non-significantly different cycle lengths divided the year into roughly 4 groupings; December-February; March; April-September; and October-November. These groups match approximately with the known seasonal behaviours of spawning, post-spawning migration, summer feeding, and pre-spawning migration.

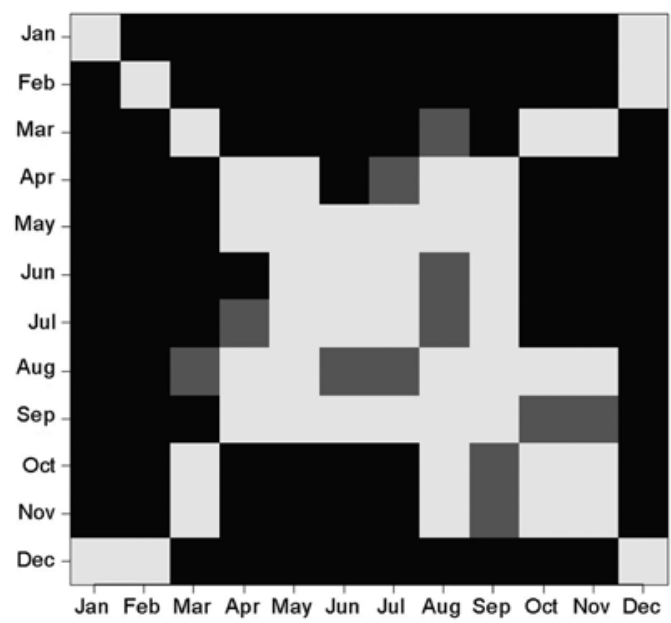

Fig. 5. Pleuronectes platessa. Significant differences in seasonal cycle lengths in North Sea plaice, identified using pairwise Wilcoxon tests. Light grey: not significantly different, dark grey: significant at $95 \%$, black: significant at $99 \%$
When the data were split according to the 3 geographically discrete feeding aggregations (Fig. 6); 1-way ANOVA revealed a significant (at 95\% confidence) difference between these $(F=3.427$; $\mathrm{p}=0.037)$. The results of pair-wise Wilcoxon tests revealed that northern area plaice demonstrated significantly lower levels of tidal activity than western area plaice $(\mathrm{p}=$ 0.018). Levels of tidal activity were not significantly different between northern and eastern ( $p=0.606)$, or western and eastern subunits $(p=0.252)$. Diel cycles occurred throughout the year, in all subunits (Fig. 6). By contrast, tidal cycles mainly occurred during the periods of migration, and the duration of tidal swimming varied between subunits (Northern: December-February; Western: October-February; Eastern: OctoberMarch).

\section{DISCUSSION}

Spatial and temporal variations in swimming activity of plaice in the North Sea were examined in relation to the propensity of these fish to migrate using the tidal currents. As predicted, the fish spent most time swimming in mid-water during the time of expected migration and spawning. However, with the exception of the fish tagged with the older and larger data storage tags (DST1s), a comparison of the average amount of time spent swimming by plaice in the different areas showed no significant difference between the groups. This was unexpected, as it had been predicted that those fish not displaying selective tidal stream transport (STST) would make directed movement across the sea-bed, with little or no requirement for swimming into mid-water.

Analysis of the timing of swimming periods versus rest periods (based on cycle length frequency) successfully identified repeated patterns of behaviour. Tidal patterns of activity were identified in plaice from the northern subunit, albeit at a significantly lower frequency than eastern and western area plaice; this was surprising because here the tidal currents are insufficiently strong to allow the efficient use of STST. Tidal cycles of activity occurred predominantly during migration in all 3 groups.

\section{Spatial variation in swimming activity}

The results confirm previous observations: that swimming in mid-water by plaice is a behaviour associated with the annual spawning migration (Greer Walker et al. 1978, Arnold \& Metcalfe 1996, Hunter et al. 2004c), with very few fish leaving the sea-bed during the summer months. Although there was no statistically significant 

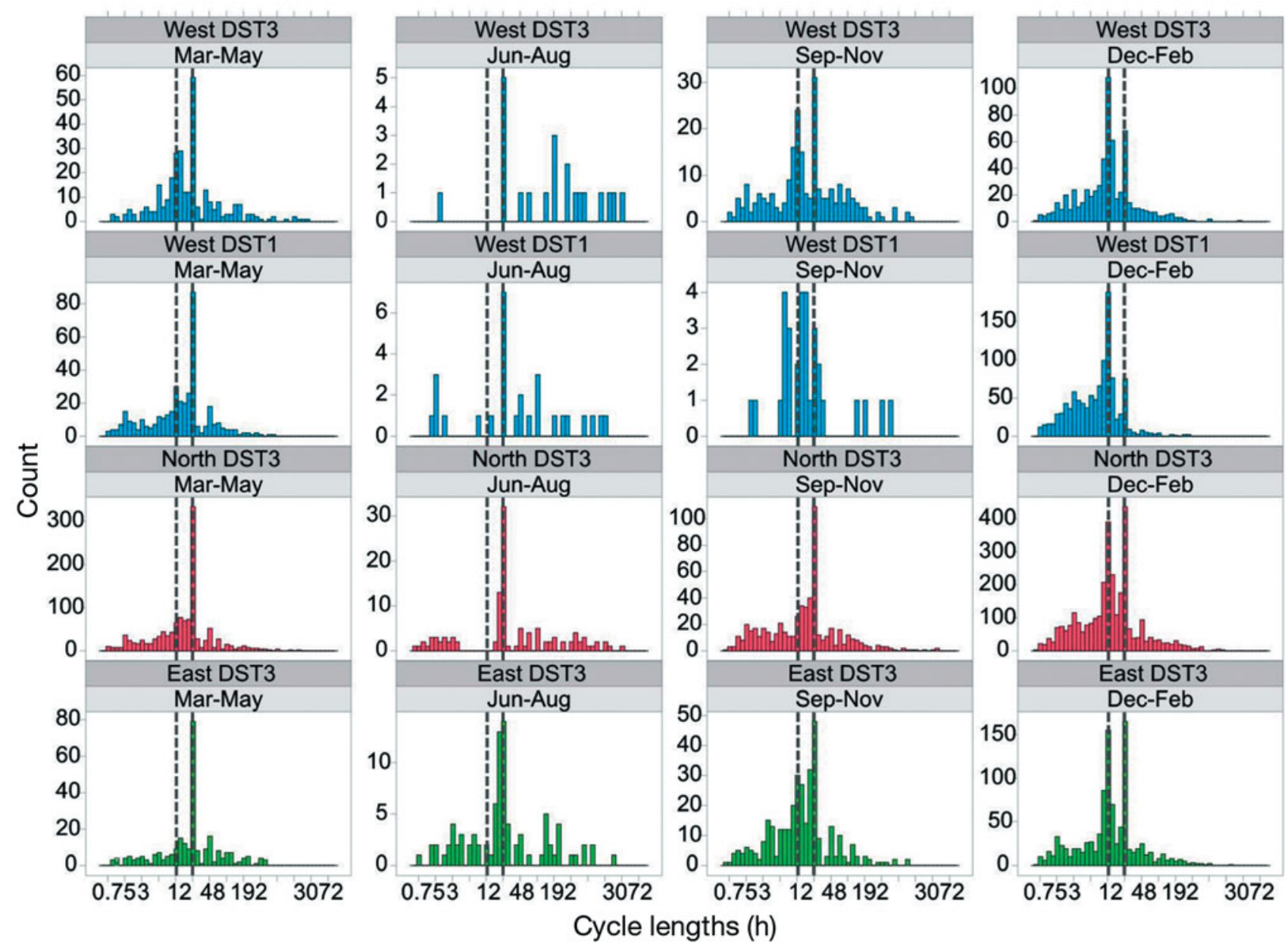

Fig. 6. Pleuronectes platessa. Frequency of occurrence of cycle lengths of swimming activity of North Sea plaice, broken down quarterly and by area

difference associated with swimming times between the 3 population subunits, the transformed swimming times were marginally higher in the East, followed by West then North. There was, however, a clear effect of tagtype, and a significant difference between the swimming times of DST1 West and DST3 West fish.

Although the minimum size of DST1 tagged fish was larger (40 cm as opposed to $35 \mathrm{~cm}$ ), it seems unlikely that this would account for any behavioural difference, since the average size of the tagged fish that were returned by the fishery was similar $(43.8 \pm 4.7 \mathrm{~cm}$ for DST1 compared with $40.3 \pm 3.9$ for DST3s). Following experimental work looking at the effects of drag on acoustically tagged plaice, Arnold \& Holford (1978) suggested that the additional mass of the tag on negatively buoyant plaice may actually lower energy expenditure by aiding station holding on the sea-bed in a current of a given speed, and may also reduce work against the lift force exerted by the current. However, it is noted that the DST1 was both significantly heavier (the acoustic tags weighed $8.3 \mathrm{~g}$ in air), and also had a different shape (Metcalfe \& Arnold 1998), being streamlined and flush against the fish, rather than being trailed. Furthermore, there seems no obvious basis to explain why the brief duration that DST1 fish were kept in captivity could be responsible for increased long-term activity levels following the return of the tagged fish to the wild.

Most of the DST1 West fish were released during December-January at Smith's Knoll where, with an average tidal velocity of approximately $60 \mathrm{~cm} \mathrm{~s}^{-1}$, all of the tagged fish should have been readily able to use STST (Metcalfe et al. 1990). Batch 3.4 was also released at Smith's Knoll, but these fish were released in February (towards the end of the migration season), when most fish were returning to their summer feeding areas; only 2 of those fish recorded data all the way through to migration the following season.

The use of the different tags and methodologies employed cannot be discounted as being responsible 
for the differences observed; however it is suggested that the lower swimming times observed for the DST3 West fish were more likely due to lack of replication in the very fast flowing tidal currents at the time of peak migration (Hunter et al. 2004c). This observation is supported by the between-batch analysis for the western fish; this suggests a N-S gradient in the total number of hours spent in mid-water, with the more northern of the West releases spending least time in mid-water. This would also correlate with the decreasing strength of the western tidal stream on moving northwards (Fig. 1).

The above explanation further suggests that the average swimming times for western DST3 plaice may be under-estimated, which would help to explain why no significant area effect was observed. The highest average DST3 swimming times were in fact observed in the East group, which also occur in an area adjacent to a fast-flowing tidal stream, although the tidal currents on the Continental coast are slower than those in the Southern Bight and English Channel (Huntley 1980).

The observation of significant levels of mid-water swimming by migrating northern plaice is surprising, not only because the tidal currents in the central North Sea are insufficiently strong to permit efficient STST $\left(<10 \mathrm{~cm} \mathrm{~s}^{-1}\right)$, but because they also flow along a predominantly $\mathrm{E}-\mathrm{W}$ axis and therefore provide neither transport nor guidance to the more southerly located spawning grounds (Harding et al. 1978). This suggests that swimming in itself also forms an important component in pre-spawning and post-spawning behaviour in addition to transport.

Previous observations of plaice crossing Dogger Bank Tail End (a submarine bank which bisects the route of northern plaice between feeding grounds and spawning areas), has shown highly synchronous activity in migrating plaice, and a much more protracted pre-spawning than post-spawning migration (Hunter et al. 2003). It is therefore conceivable that swimming activity forms a component of social behaviour and mate choice (Solmundsson et al. 2003). Since the northern fish must find their spawning areas without the assistance of tidal streams, swimming may also be necessary for navigation by allowing orientation to external cues e.g. geophysical cues (Metcalfe et al. 1993).

\section{Cycle length frequencies}

As in previous studies of both aquarium-held adult plaice (Page 1997) and of free-swimming DST1-tagged plaice in the southern North Sea (Hunter et al. 2004c), clearly defined vertical activity patterns were observed throughout the North Sea. These included diel and tidal patterns of activity, previously observed to dominate the activity rhythms of plaice in the southern North Sea (Hunter et al. 2004c). However, evidence was also found of repeated multi-diel patterns of behavior; these varied in prevalence throughout the year, and between geographical subunits. However, no visible peak occurred at 336 h (14 d), $(\ln 336=5.82$; bin range is $330.3-347.2 \mathrm{~h}$ ), suggesting that the significant $14 \mathrm{~d}$ spring-neap tidal behaviour (using averaged whole population data) reported by Hunter et al. (2004c) was an artefact of multiple recorded cycles.

Behavioural and physiological drivers behind the newly observed behaviours are not immediately apparent. Peaks were also visible in the log-binned plot near 72 and $96 \mathrm{~h}$, suggesting tri-diel and quad-diel behaviour. These behaviours are therefore not repeated diel activity patterns, but consist of swimming activity on every 3rd or 4th day; results from this study suggest that diel patterns are not always repeated mechanistically, and that migrating fish do not always swim on a daily basis.

While mid-water swimming as a feature of the migration in northern area plaice was not expected, neither was the occurrence of modest tidal periodicity. Plaice are exposed to tidal cycles from the time of hatching onwards; juvenile fish use these to cue their daily movements in the shallow inter-tidal zone (see review by Gibson 1997), and adult fish take advantage of them through the use of STST in fast-flowing tidal currents (Metcalfe et al. 2006). Tidal patterns of activity in this instance may provide evidence that entrainment to tidal periodicity is carried over from juvenile into adult life (Gibson 1982).

Many previous studies in fish vertical activity (swimming) have considered patterns in depth, rather than the simplified rest-swim series used here (e.g. Arnold et al. 1994, Pálsson \& Thorsteinsson 2003). By using rest-swim series, environmental variation over a wide geographical range was removed, thus standardising the behaviour observed over the sample population; the data suggest that the modal cycle frequency is a good indicator of the dominant behaviour throughout the year (Fig. 2).

The observed seasonal variation in plaice swimming behaviour has parallels with seasonally-linked behaviours described for North Sea cod (Hobson et al. 2007), based on an analysis of skewness in continuous cod DST depth data with respect to time spent on the seabed. Cod DST data have also recently been successfully analysed using wavelet analysis (Subbey et al. 2008). However, standard wavelet theory and spectral analysis deals with continuous response variables (such as fish depth), and is therefore inappropriate for the binary rest-swim time series used here. While 
wavelet theory can be adapted to binary data (e.g. Swanson \& Tewfik 1996), since the rest-swim series described already contains exact cycle lengths, it is suspected that this approach would do little to enhance understanding (and prediction) of seasonal variation in cyclic swimming behaviour by plaice.

\section{Implications for conservation and assessment}

The total amount of time seabed dwelling fish spend swimming in mid-water (versus the total amount of time spent resting on the sea-bed) significantly affects their availability to the different gear types deployed by commercial fishing and biological survey vessels (Aglen et al. 1999). For many species, time spent swimming in mid-water will be influenced by size, maturity stage, time of year; sometimes also by physical characteristics of the environment, including substrate type and water currents (Metcalfe et al. 2008a).

The results from the current study provide one of few examples where the behaviour of a fish stock has been recorded across a large part of its overall geographical range (and hence its principal fishery), and throughout all seasons of the year. DST studies of plaice have already largely confirmed the observations from acoustic-tracking and mid-water trawling experiments made at specific locations at particular times of year (e.g. Greer Walker et al. 1978, Arnold \& Metcalfe 1996), and have also provided insights into migration (Metcalfe \& Arnold 1997, Hunter et al. 2004a), distribution (Hunter et al. 2004b) and reproductive behaviour (Hunter et al. 2003, Solmundsson et al. 2003). This work now allows the characterisation of swimming times and patterns of activity across the North Sea for the first time.

The observation that very few plaice left the seabed during the summer months reinforces previous findings concerning efficiency of trawl surveys (Hunter et al. 2004c). Plaice are mostly caught by beam trawl (Poos \& Rijnsdorp 2007) when the fish are located on the sea-bed. It can therefore be inferred that the most appropriate time to survey these fish to maximise catch would be during the months of May-August; restricting fishing effort to daytime trawls would also help, given that most swimming activity occurs nocturnally (Hunter et al. 2004c). The high cost of sea-going research currently dictates that most surveys are undertaken around the clock, and at present the English ground fish survey (which surveys using beamtrawl gear) is carried out during August/September. It is therefore probable that a small but varying proportion of the stock will not be available to survey, particularly during September when the fish start to migrate. Although this figure is unlikely to be more than $5 \%$ based on current observations, the effect could be more pronounced where activity is triggered (e.g. by the onset of darkness).

These data also have a direct application in the development of individual-based plaice migration models, which aim to assess the potential impacts of proposed management measures such as closed areas or seasons (Baum et al. 2003). Although the parameterisation of biologically realistic fisheries models is inherently compromised by the quality of the data available (Machiels et al. 2006), the results from studies using DSTs not only provide an accurate estimation of rates of fish migration (Kell et al. 2004), but such models can be much more finely tuned to the availability of fish to capture by the incorporation of spatial and temporal distribution of swimming activity indices.

\section{CONCLUSIONS}

The results describe spatial and temporal differences in the swimming activity of plaice across the North Sea. Off-bottom swimming and tidal activity were most pronounced in (but not exclusive to) areas of fast-flowing tidal currents, and were observed more frequently during times of migration and reproduction. A cyclelength analysis divided the year into 4 blocks of activity that closely corresponded with described seasonal behaviours. Since the approach described is largely generic, it may be applied to any species exhibiting rest-swim cycles of activity, and may prove a useful tool for describing behaviour in other sea-bed dwelling species.

Acknowledgements. This work was funded by the Department of Environment, Food and Rural Affairs (formerly $\mathrm{MAFF}$ ), and the Commission of European Communities Agriculture and Fisheries (FAIR) specific RTD programme, PL962079, 'Migration, distribution and spatial dynamics of plaice and sole in the North Sea and adjacent areas'. It does not necessarily reflect their views and in no way anticipates the Commission's future policy in this area. Final versions of the figures were prepared by I. Gooch and D. Riches. D. Maxwell provided additional support for statistical analysis of the results. We thank everyone involved in the release of tagged plaice and return of the electronic tags, and the anonymous referees who made valuable contributions to the final version of the manuscript.

\section{LITERATURE CITED}

Aglen A, Engås A, Huse I, Michalsen K, Stensholt BK (1999) How vertical fish distribution may affect survey results. ICES J Mar Sci 56:345-360

> Alerstam T (2006) Conflicting evidence about long-distance animal navigation. Science 313:791-794

Arnold GP (1981) Movements of fish in relation to water currents. In: Aidley DJ (ed) Animal migration. Society for 
Experimental Biology Seminar Series 13:55-79

Arnold GP, Holford BD (1978) The physical effects of an acoustic tag on the swimming performance of plaice and cod. J Cons Int Explor Mer 38:189-200

Arnold GP, Metcalfe JD (1996) Seasonal migrations of plaice (Pleuronectes platessa) through the Dover Strait. Mar Biol 127:151-160

Arnold GP, Walker MG, Emerson LS, Holford BH (1994) Movements of cod (Gadus morhua L.) in relation to the tidal streams in the southern North Sea. ICES J Mar Sci 51: 207-232

Bannister RCA (1978) Changes in plaice stocks and plaice fisheries in the North Sea. Rapp P-V Reun Cons Int Explor Mer 172:86-101

Baum JK, Myers RA, Kehler DG, Worm B, Harley SJ, Doherty PA (2003) Collapse and conservation of shark populations in the Northwest Atlantic. Science 299:389-392

Benjamini Y, Yekutieli D (2001) The control of the false discovery rate in multiple testing under dependency. Ann Stat 29:1165-1188

Benoit HP, Swain DP (2003) Accounting for length- and depth-dependent diel variation in catchability of fish and invertebrates in an annual bottom trawl survey. ICES J Mar Sci 60:1298-1317

Bjørndal TA, Gordon DVB, Kaitala VC, Lindroos MD (2004) International management strategies for a straddling fish stock: A bio-economic simulation model of the Norwegian spring-spawning herring fishery. Environ Resour Econ 29: 435-457

Block BA, Teo SLH, Walli A, Boustany A and others (2005) Electronic tagging and population structure of Atlantic bluefin tuna. Nature 434:1121-1127

Box GEP, Cox DR (1964) An analysis of transformations (with discussion). J R Stat Soc B 26:211-252

Brower LP (1995) Understanding and misunderstanding the migration of the monarch butterfly (Nymphalidae) in North America: 1857-1995. J Lepid Soc 49:304-385

Brown RS, Cooke SJ, Anderson WG, McKinley RS (1999) Evidence to challenge the ' $2 \%$ rule' for biotelemetry. N Am J Fish Manage 19:867-871

Buckley AA, Arnold GP (2001) Orientation and swimming speed of plaice migrating by selective tidal stream transport. In: Sibert JR, Nielsen JL (eds) Electronic tagging and tracking in marine fisheries. Kluwer Academic Publishers, Dordecht, p 315-330

$>$ Casey JM, Myers RA (1998) Diel variation in trawl catchability: is it as clear as day and night? Can J Fish Aquat Sci 55: $2329-2340$

Gibson RN (1982) The effect of hydrostatic pressure cycles on the activity of young plaice Pleuronectes platessa. J Mar Biol Assoc UK 62:621-635

Gibson RN (1997) Behaviour and distribution of flatfishes. J Sea Res 37:241-256

Greer Walker M, Harden Jones FR, Arnold GP (1978) The movements of plaice (Pleuronectes platessa L.) tracked in the open sea. J Cons Int Explor Mer 38:58-86

Harden Jones FR, Arnold GP, Greer Walker M, Scholes P (1979) Selective tidal stream transport and the migration of plaice (Pleuronectes platessa L.) in the southern North Sea. J Cons Int Explor Mer 38:331-337

Harding D, Nichols JH, Tungate DS (1978) The spawning of plaice (Pleuronectes platessa L.) in the Southern Bight. Rapp P-V Reun Cons Int Explor Mer 172:102-113

> Hobson VJ, Righton D, Metcalfe JD, Hays GC (2007) Vertical movements of North Sea cod. Mar Ecol Prog Ser 347: 101-110

Hunter E, Metcalfe JD, Reynolds JD (2003) Migration route and spawning area fidelity by North Sea plaice. Proc R Soc Biol Sci Ser B 270:2097-2103

Hunter E, Metcalfe JD, Holford BH, Arnold GP (2004a) Geolocation of free-ranging fish on the European continental shelf as determined from environmental variables. II. Reconstruction of plaice ground-tracks. Mar Biol 144: 787-798

Hunter E, Metcalfe JD, Arnold GP, Reynolds JD (2004b) Impacts of migratory behaviour on population structure in North Sea plaice. J Anim Ecol 73:377-385

> Hunter E, Metcalfe JD, O'Brien CM, Arnold GP, Reynolds JD (2004c) Vertical activity patterns of free-swimming adult plaice in the southern North Sea. Mar Ecol Prog Ser 279: 261-273

Huntley DA (1980) Tides of the north-west European Continental Shelf. In: Banner FT, Collins MB, Massie KS (eds) The North-west European Shelf seas: the sea bed and the sea in motion. II. Physical and chemical oceanography and physical resources. Elsevier, Amsterdam

Jepsen N, Schreck C, Clements S, Thorstad EB (2005) A brief discussion on the $2 \% \mathrm{tag} / \mathrm{bodymass}$ rule of thumb. In: Spedicato MT, Lembo G, Marmulla G (eds) Aquatic telemetry: advances and applications. Proceedings of the Fifth Conference on Fish Telemetry held in Europe. Ustica, Italy, 9-13 June 2003. Rome, FAO/COISPA, p 255-259

Kell LT, Fromentin JM (2007) Evaluation of the robustness of maximum sustainable yield based management strategies to variations in carrying capacity or migration pattern of Atlantic bluefin tuna (Thunnus thynnus). Can J Fish Aquat Sci 64:837-847

- Kell LT, Scott R, Hunter E (2004) Implications for current management advice for North Sea plaice: Part I. Migration between the North Sea and English Channel. J Sea Res 51:287-299

$>$ Kuipers B (1973) On the tidal migration of young plaice (Pleuronectes platessa) in the Wadden Sea. Neth J Sea Res 6: 376-388

Machiels MAM, Kraak SBM, van Beek FA (2006) Evaluation of a management plan as proposed by the European Commission in 2006 for fisheries exploiting stocks of plaice and sole in the North Sea. Wageningen IMARES, IJmuiden

Metcalfe JD, Arnold GP (1997) Tracking fish with electronic tags. Nature 387:665-666

Metcalfe JD, Arnold GP (1998) Tracking migrating fish with electronic tags. In: McCarthy M (ed) EEZ technology: A review of advanced technologies for the management of EEZs worldwide. 2nd edn. ICG Publishing, London, p 199-206

Metcalfe JD, Arnold GP, Webb P (1990) The energetics of migration by selective tidal stream transport: an analysis for plaice tracked in the southern North Sea. J Mar Biol Assoc UK 70:149-162

Metcalfe JD, Holford BH, Arnold GP (1993) Orientation of plaice (Pleuronectes platessa) in the open sea: evidence for the use of external directional clues. Mar Biol 117:559-566

Metcalfe JD, Arnold GP, McDowall PW (2002) Migration. In: Hart PJB, Reynolds JD (eds) Handbook of fish biology and fisheries. Vol 1. Fish Biology. Blackwell Publishing, Oxford, p 175-199

Metcalfe JD, Hunter E, Buckley AA (2006) Currents, clues and clocks: the migratory behaviour of North Sea plaice. Mar Freshw Behav Physiol 39:25-36

Metcalfe JD, Eastwood PD, Righton D, Hunter E (2008a) Migration and habitat choice. In: Braithewaite V, Magnhagen C, Forsgren E (eds) Fish behaviour. Science Publishers, Enfield, p 187-234 
Metcalfe JD, Righton DA, Hunter E, Neville S, Mills D (2008b) New technologies for the advancement of fisheries science. In: Payne A, Cotter J, Potter ECE (eds) Advances in fisheries science: 50 years on from Beverton and Holt. Blackwell Publishing, Oxford, p 255-279

Michalsen K, Godø OR, Fernö A (1996) Diel variation in the catchability of gadoids and its influence on the reliability of abundance indices. ICES J Mar Sci 53:389-395

Nichol DG, Somerton DA (2002) Diurnal vertical migration of the Atcka mackerel Pleurogrammus monopterygius as shown by archival tags. Mar Ecol Prog Ser 239:193-207

Page NS (1997) Rhythmic behaviour in 2 species of marine flatfish: Solenette (Buglossidium luteum Risso) and plaice (Pleuronectes platessa L.). PhD dissertation, University of Birmingham, UK

> Perry RW, Adams NS, Rondorf DW (2001) Buoyancy compensation of juvenile Chinook salmon implanted with 2 different size dummy transmitters. Trans Am Fish Soc 130: $46-52$

Pittman SJ, McAlpine CA (2003) Movements of marine fish and decapod crustaceans: Process, theory and application. Adv Mar Biol 44:205-294

Poos JJ, Rijnsdorp AR (2007) The dynamics of small-scale

Editorial responsibility: Konstantinos Stergiou,

Thessaloniki, Greece patchiness of plaice and sole as reflected in the catch rates of the Dutch beam trawl fleet and its implications for the fleet dynamics. J Sea Res 58:100-112

Priede IG, Holliday FGT (1980) The use of a new tilting respirometer to investigate some aspects of metabolism and swimming activity of the plaice (Pleuronectes platessa L.). J Exp Biol 85:295-309

Solmundsson J, Karlsson K, Palsson J (2003) Sexual differences in spawning behaviour and catchability of plaice (Pleuronectes platessa) west of Iceland. Fish Res 61:57-71

Subbey S, Michalsen K, Nilsen GK (2008) A tool for analyzing information from data storage tags: the continuous wavelet transform (CWT). Rev Fish Biol Fish 18:301-312

Swanson MD, Tewfik AH (1996) A binary wavelet decomposition of binary images. IEEE Trans Image Process 5: $1637-1650$

Venables WN, Ripley BD (2002) Modern applied statistics with S. Springer-Verlag, New York

Weihs D (1978) Tidal stream transport as an efficient method for migration. J Cons Int Explor Mer 38:92-99

Winter JD (1996) Advances in underwater biotelemetry. In: Murphy BR, Willis DW (eds) Fisheries techniques, 2nd edn. American Fisheries Society, Bethesda, MD, p 555-590

Submitted: December 8, 2008; Accepted: July 13, 2009

Proofs received from author(s): October 13, 2009 